\title{
Effect of moisture on thermal conductivity of a cementitious composite
}

\author{
Eva Mňahončáková ${ }^{1}$, Milena Jiřičková ${ }^{2}, Z$ byšek Pavlík ${ }^{2}$, Lukáš Fiala ${ }^{2}$, Pavla Rovnaníková ${ }^{3}$, \\ Patrik Bayer ${ }^{3}$, Robert Černý ${ }^{2}$ \\ ${ }^{1}$ Department of Physics, Faculty of Civil Engineering, Czech Technical University, \\ Thákurova 7, 16629 Prague 6, Czech Republic \\ ${ }^{2}$ Department of Structural Mechanics, Faculty of Civil Engineering, Czech Technical \\ University, Thákurova 7, 16629 Prague 6, Czech Republic \\ ${ }^{3}$ Institute of Chemistry, Faculty of Civil Engineering, Brno University of Technology, \\ Žižkova 17, 60200 Brno, Czech Republic
}

\begin{abstract}
The measurements of thermal conductivity of a cement-based composite material are performed in dependence on moisture content from dry state to fully water saturated state using an impulse technique. Then, the obtained data are analyzed using Brugemann and Wiener homogenization formulas. The validity of applied homogenization techniques is assessed comparing the measured and calculated results. On the basis of the experimental data and the homogenization analyses, the effects of total pore volume, pore distribution and moisture content on the thermal conductivity are discussed.
\end{abstract}

\section{Key words:}

Thermal conductivity, moisture content, cementitious composites, homogenization

\section{Introduction}

Cementitious composites contain a significant amount of pores of different size. As the thermal conductivity of the air is $0.026 \mathrm{~W} / \mathrm{mK}$ [1] and the thermal conductivity of cement stone is (depending on the amount and the type of aggregates) in the range of $1-3 \mathrm{~W} / \mathrm{mK}$ [2], both the total pore volume and the distribution of pores can affect the thermal conductivity of a cementitious material in a very significant way. In usual service conditions, cementitious composites always contain certain amount of water. The thermal conductivity of water is 0.60 $\mathrm{W} / \mathrm{mK}$ [1], which is more than 20 times higher than of the air. Therefore, if water is present in the pore space, its effect competes with the effect of air, and the thermal conductivity of a composite material can be considered as a result of this competition together with the effect of the cement matrix.

Thermal conductivity as the main heat transfer parameter was often subject of measurement for various types of cement-based composites. However, mostly just one single value was determined (see, e.g., the reviews in [2]-[4]). The dependence of thermal conductivity on moisture content was studied for instance in [5]-[8] where empirical relations were obtained but such measurements can still be considered as relatively rare.

Homogenization theories working with the concept of an effective medium were proven as very useful in a variety of applications in mechanics and in the theory of electricity and magnetism where they already belong to well established treatments (see, e.g. [9], [10]). Their utilization in heat transfer was much less frequent until now. Within the last couple of years, some references appeared on using the effective media theories for estimation of thermal conductivity of refractory materials [11], [12], syntactic foams [13], polymer-based composites [14] but not a single reference was found by the authors for cementitious composites, in common sources. 
In this paper, the effects of the amount and the size of the pores on thermal conductivity of cement-based composites are studied in the conditions when these are either empty or partially or fully filled by water. The analysis is performed using both experiments and effective medium theories for a carbon fiber reinforced cement composite exposed to different external conditions before the measurement.

\section{Experimental methods}

The thermal conductivity was determined using the commercial device ISOMET 2104 (Applied Precision, Ltd.). ISOMET 2104 is a multifunctional instrument for measuring thermal conductivity, thermal diffusivity, and volumetric heat capacity. It is equipped with various types of optional probes, needle probes are for porous, fibrous or soft materials, and surface probes are suitable for hard materials. The measurement is based on the analysis of the temperature response of the analyzed material to heat flow impulses. The heat flow is induced by electrical heating using a resistor heater having a direct thermal contact with the surface of the sample. The measurements in this paper were done in dependence on moisture content.

\section{Homogenization techniques}

In terms of a homogenization procedure, a porous material can be considered basically as a mixture of three phases, namely solid, liquid and gaseous phase. In the cement based material studied in this work, the solid phase is represented by cement, microdorsilite, carbon fibers and wollastonite, the liquid phase by water and the gaseous phase by air. Therefore, the homogenization should be performed in three steps. The first task is the determination of thermal conductivity of the cement matrix. This can be done on the basis of the known thermal conductivities and amounts of its constituents. The second step should be the determination of thermal conductivity of the dry material where only the solid and gaseous phases are to be considered. This can be realized using the volumetric fraction of the air obtained in porosimetric measurements and the known thermal conductivities of the matrix and the air. For the evaluation of thermal conductivity of the whole material, which is the third and last step of the homogenization procedure, the mixing is performed for cement matrix, air and water.

In this work, three Bruggeman-type homogenization formulas (see [15]) were employed for the calculation of thermal conductivity of the cement matrix-air-water system. The first of them, the original one, was proposed for spherical inclusions, the second assumes acicular orientation of inclusions and the third was derived for their board-like (disk) orientation. The applied mixing formulas are described in equations (1)-(3), respectively,

$$
\begin{aligned}
& \lambda_{\text {eff }}=\lambda_{M}+\sum f_{j}\left(\lambda_{j}-\lambda_{M}\right) \cdot \frac{3 \lambda_{\text {eff }}}{2 \lambda_{\text {eff }}+\lambda_{j}}, \\
& \lambda_{\text {eff }}=\lambda_{M}+\sum f_{j}\left(\lambda_{j}-\lambda_{M}\right) \cdot \frac{5 \lambda_{\text {eff }}+\lambda_{j}}{3 \lambda_{\text {eff }}+3 \lambda_{j}}, \\
& \lambda_{\text {eff }}=\lambda_{M}+\sum f_{j}\left(\lambda_{j}-\lambda_{M}\right) \cdot \frac{2 \lambda_{j}+\lambda_{\text {eff }}}{3 \lambda_{j}},
\end{aligned}
$$

where $\lambda_{\text {eff }}$ is the thermal conductivity of the studied material, $\lambda_{M}$ the thermal conductivity of cement matrix $(1.6 \mathrm{~W} / \mathrm{mK})$ which was determined using the Rayleigh [16] mixing rule (4)

$$
\frac{\lambda_{M}-1}{\lambda_{M}+2}=f_{c}\left(\frac{\lambda_{c}-1}{\lambda_{c}+2}\right)+f_{m}\left(\frac{\lambda_{m}-1}{\lambda_{m}+2}\right)+f_{c f}\left(\frac{\lambda_{c f}-1}{\lambda_{c f}+2}\right)+f_{w}\left(\frac{\lambda_{w}-1}{\lambda_{w}+2}\right) \text {, }
$$


from the known thermal conductivities of cement, microdorsilite, carbon fibers and wollastonite [1], $f_{j}$ the volumetric fraction of air or water, $\lambda_{j}$ the thermal conductivity of air $(0.026 \mathrm{~W} / \mathrm{mK})$ or water $(0.6 \mathrm{~W} / \mathrm{mK})$.

In equation (4), $f_{c}$ is the volumetric fraction of cement, $f_{m}$ the volumetric fraction of microdorsilite, $f_{c \mathrm{f}}$ the volumetric fraction of carbon fibers, $f_{w}$ the volumetric fraction of wollastonite, $\lambda_{c}$ the thermal conductivity of cement, $\lambda_{m}$ the thermal conductivity microdorsilite, $\lambda_{c f}$ the thermal conductivity of carbon fibers, $\lambda_{w}$ the thermal conductivity of wollastonite.

For the verification of obtained results, Wiener's bounds [17] for parallel (5) and serial model (6) were used. These bounds in fact represent upper and lower limits of the thermal conductivity vs. water content function. The Wiener's bounds are given in the following relations

$$
\begin{aligned}
\lambda_{\text {eff }}= & \frac{1}{\frac{f_{1}}{\lambda_{1}}+\frac{f_{2}}{\lambda_{2}}+\frac{f_{3}}{\lambda_{3}}}, \\
\lambda_{\text {eff }}= & f_{1} \lambda_{1}+f_{2} \lambda_{2}+f_{3} \lambda_{3},
\end{aligned}
$$

where $\lambda_{\text {eff }}$ is the thermal conductivity of the studied material, $f_{1}-f_{3}$ the volumetric fractions of the particular constituents of the porous body, $\lambda_{1}-\lambda_{3}$ the thermal conductivities of the constituents.

\section{Materials and samples}

The measurements were done on carbon fiber reinforced cement (CFRC) produced in the laboratories of VUSH Brno (CZ). The composition of CFRC material (calculated among the dry substances only) is presented in Table 1. Portland cement used was CEM I 52.5 produced in cement factory Mokrá (CZ), carbon fiber was PAN-type. The water/cement ratio corresponding to the amount of water added into the mixture was 0.9 .

Table 1 Composition of the carbon fiber reinforced cement composite in mass- $\%$ of dry substances

\begin{tabular}{|c|c|c|c|c|c|c|c|}
\hline Cement & $\begin{array}{c}\text { Micro- } \\
\text { dorsilite }\end{array}$ & $\begin{array}{c}\text { Plasti- } \\
\text { cizer }\end{array}$ & $\begin{array}{c}\text { Carbon } \\
\text { fiber }\end{array}$ & $\begin{array}{c}\text { Wolla- } \\
\text { stonite }\end{array}$ & $\begin{array}{c}\text { Methyl- } \\
\text { cellulose }\end{array}$ & Defoamer & Microsilica \\
\hline 39.71 & 16.50 & 0.98 & 0.98 & 39.60 & 0.11 & 0.16 & 1.96 \\
\hline
\end{tabular}

The samples were produced using a successive homogenization procedure. First, wollastonite, microdorsilite and microsilica were homogenized in a mixing device, then cement and methylcellulose were added and the dry mixture was homogenized again. The dry well homogenized mixture was thoroughly mixed with water, defoamer and plasticizer. Then, the carbon fibers were added and the mixture shortly mixed again. Finally, the prepared mixture was vacuum-treated in special molds with perforated bottom. The material was autoclaved at $180^{\circ} \mathrm{C}$ and then dried at $105^{\circ} \mathrm{C}$. After the time period of 28 days after mixing, the samples were prepared for testing.

In the experimental measurements, five various specimen pre-treatment conditions were tested: 
Reference specimen not exposed to any load.

$>$ Specimen exposed to a gradual temperature increase up to 600,800 and $1000^{\circ} \mathrm{C}$ during two hours, then left for another 2 hours at the final temperature and slowly cooled.

$>$ Specimen exposed to tensile load up to breaking.

The measured samples were cut from the plates of $10 \mathrm{~mm}$ thickness. Five specimens $60 \times 60$ $\mathrm{x} 10 \mathrm{~mm}$ for every pre-treatment were used in the thermal conductivity measurements.

Before the measurements, all specimens were dried in an oven at $110{ }^{\circ} \mathrm{C}$. The measurements on both reference and pre-treated specimens were performed in the laboratory condition at $24 \pm 1{ }^{\circ} \mathrm{C}$ and $30-35 \%$ relative humidity.

\section{Results and discussion}

Tables 2, 3 show bulk density and thermal conductivity of the studied cementitious composite in dry state. The tensile load was not found to affect the thermal conductivity in dry state in a very significant way. We observed a $10 \%$ increase (see Table 3 ) compared to the reference specimens. Also, the moisture dependence of the thermal conductivity of the samples subjected to tensile load did not exhibit any remarkable changes compared to the reference state, as illustrated in Fig. 1. The only exception was in the range of highest moistures where the tensile load resulted in a $30 \%$ increase of thermal conductivity. This may be related to the tensile cracks appearance that increased the effective porosity in certain range but the effect of nonhomogeneities in the material specimens cannot be excluded as well. Mercury intrusion porosimetry (MIP) results in Fig. 2 did not show any variations of the pore distribution in comparison with the reference specimen. This is, however, quite logical because the small size of the specimens for MIP measurements does not allow for discovering the majority of cracks that mostly have larger dimensions.

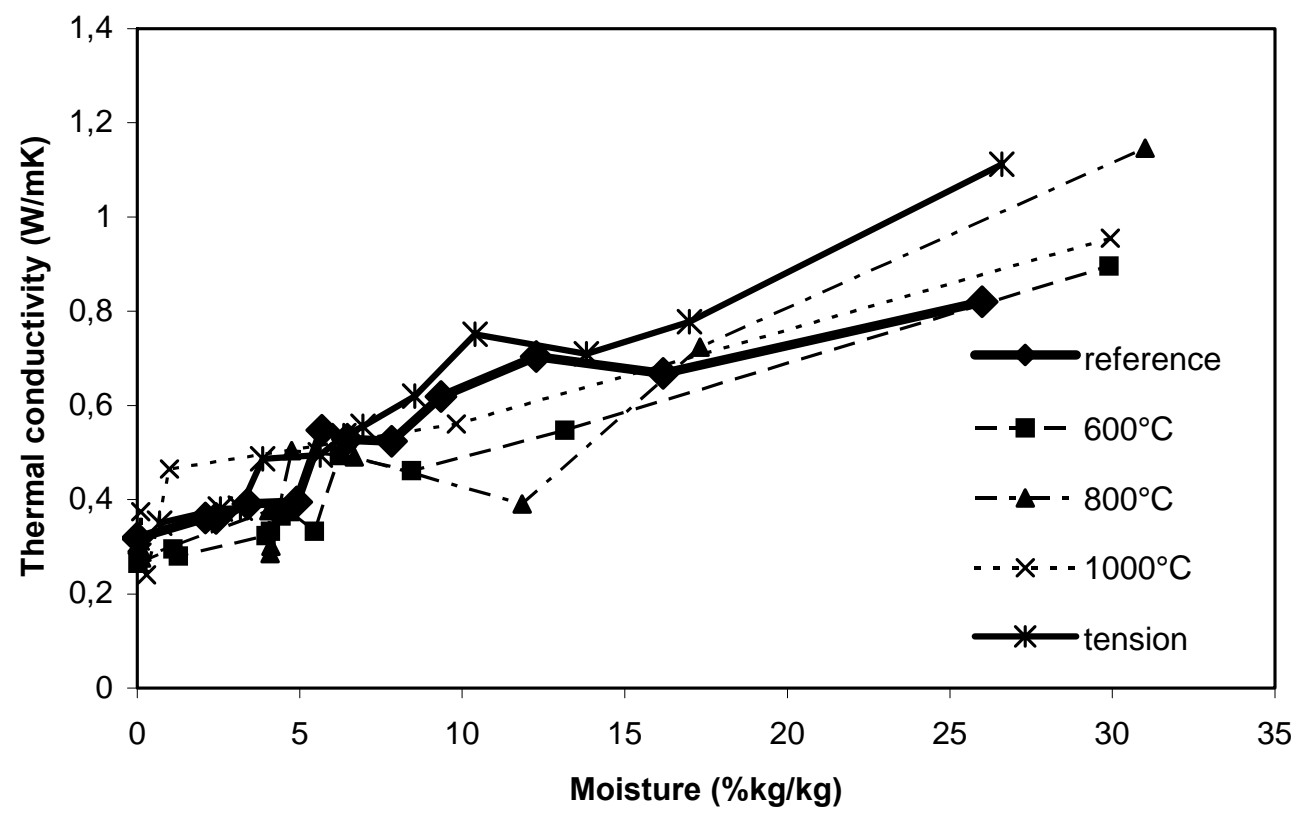

Fig. 1 Experimentally determined thermal conductivity of the studied material as a function of moisture content 
Table 2 Bulk density of the carbon fiber reinforced cement composite

\begin{tabular}{|c|c|c|c|c|c|}
\hline $\begin{array}{c}\text { Specimen } \\
\text { type }\end{array}$ & reference & $600^{\circ} \mathrm{C}$ & $800^{\circ} \mathrm{C}$ & $1000^{\circ} \mathrm{C}$ & tension \\
\hline $\begin{array}{c}\text { Bulk density } \\
{\left[\mathrm{kg} / \mathrm{m}^{3}\right]}\end{array}$ & 1468 & 1378 & 1344 & 1352 & 1430 \\
\hline
\end{tabular}

Table 3 Thermal conductivity of the carbon fiber reinforced cement composite in dry state

\begin{tabular}{|c|c|c|c|c|c|}
\hline $\begin{array}{c}\text { Specimen } \\
\text { type }\end{array}$ & reference & $600^{\circ} \mathrm{C}$ & $800^{\circ} \mathrm{C}$ & $1000^{\circ} \mathrm{C}$ & tension \\
\hline $\begin{array}{c}\text { Thermal } \\
\text { conductivity } \\
{[\mathrm{W} / \mathrm{mK}]}\end{array}$ & 0.318 & 0.265 & 0.303 & 0.337 & 0.350 \\
\hline
\end{tabular}

Table 3 shows that the studied material did not seem to be affected by the thermal pretreatment very much. Its thermal conductivity after the $600^{\circ} \mathrm{C}$ pre-heating decreased by about $15 \%$ compared to the reference specimens, for $800^{\circ} \mathrm{C}$ the decrease was only $5 \%$ and for $1000^{\circ} \mathrm{C}$ the thermal conductivity increased by $6 \%$ in comparison with the reference material. Similar features were observed in the thermal conductivity vs. moisture functions in Fig. 1.

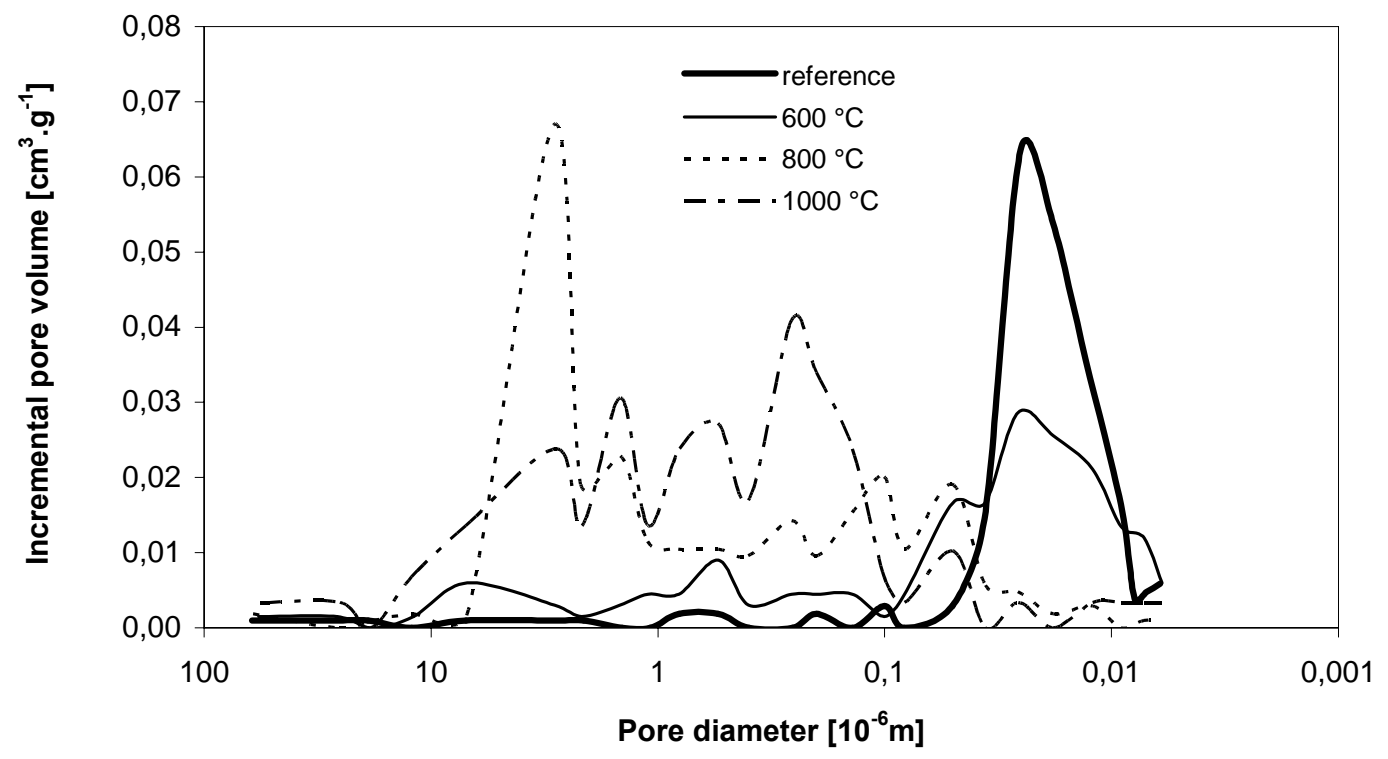

Fig. 2 Mercury intrusion porosimetry of the studied material

In looking for the correlation of thermal conductivity of thermally pre-treated samples with the changes in porosity and in the pore distribution we will analyze the data in Table 4 and Fig. 2. Table 4 shows that compared to the reference specimen, the porosity of the material for the $600^{\circ} \mathrm{C}$ pre-heating decreased by $8 \%$, for $800^{\circ} \mathrm{C}$ it increased by $22 \%$ and for $1000^{\circ} \mathrm{C}$ by $44 \%$. The changes in the pore distribution were more remarkable. For the $600^{\circ} \mathrm{C}$ pre-heating 
the most distinct peak of the incremental volume curve at $20 \mathrm{~nm}$ decreased to about one half and the amount of bigger pores increased in practically the whole range. The $800^{\circ} \mathrm{C}$ preheating then led to an almost complete reversal of the pore distribution curve. The $20 \mathrm{~nm}$ peak completely disappeared and a new peak at about $3 \mu \mathrm{m}$ became dominant. The pre-heating to $1000^{\circ} \mathrm{C}$ resulted in a remarkable increase of the amount of bigger pores in a relatively wide range of $200 \mathrm{~nm}$ to $10 \mu \mathrm{m}$.

Table 4 Global characteristics of the pore space of the carbon fiber reinforced cement composite

\begin{tabular}{|c|c|c|c|}
\hline $\begin{array}{c}\text { Material } \\
\text { sample }\end{array}$ & $\begin{array}{c}\text { Total intrusion } \\
\text { volume }\left(\mathrm{cm}^{3} / \mathrm{g}\right)\end{array}$ & $\begin{array}{c}\text { Total pore } \\
\text { area }\left(\mathrm{m}^{2} / \mathrm{g}\right)\end{array}$ & $\begin{array}{c}\text { Median pore } \\
\text { diameter }(\mu \mathrm{m})\end{array}$ \\
\hline reference & 0.216 & 42.97 & 0.0236 \\
\hline $600^{0} \mathrm{C}$ & 0.199 & 31.76 & 0.0335 \\
\hline $800^{0} \mathrm{C}$ & 0.264 & 6.65 & 0.978 \\
\hline $1000^{\circ} \mathrm{C}$ & 0.310 & 9.57 & 0.558 \\
\hline
\end{tabular}

In Figs. 3-7, there are presented the thermal conductivity vs. moisture content functions calculated using three different Bruggeman-type mixing formulas and Wiener's formulas. From the point of view of Wiener's bounds, we can see that the calculated results as well as the experimentally measured data lie between the serial and the parallel model, which basically justifies the reasonable accuracy of both experiment and calculations.

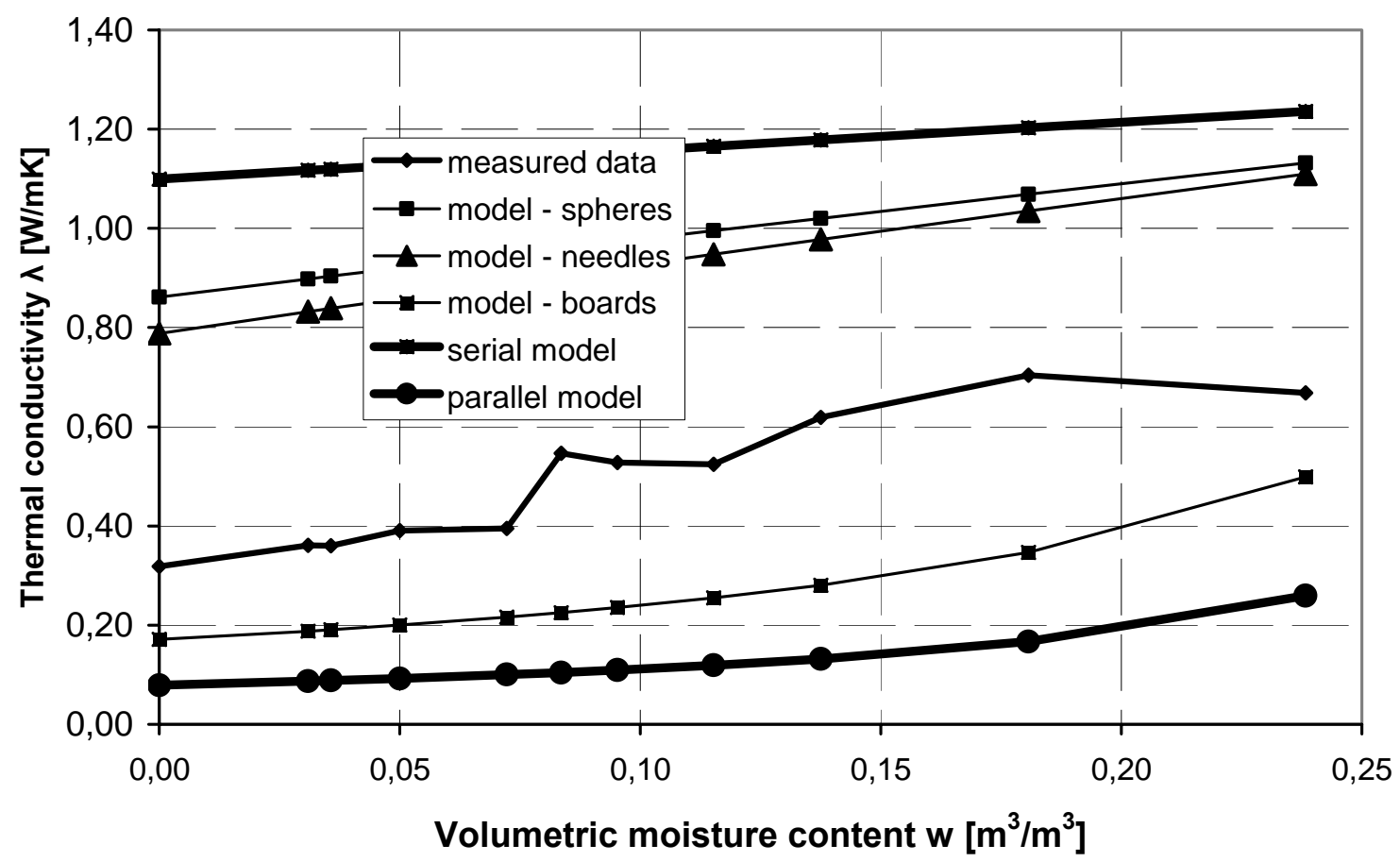

Fig.3 Measured and calculated thermal conductivity of the reference sample in dependence on moisture content 


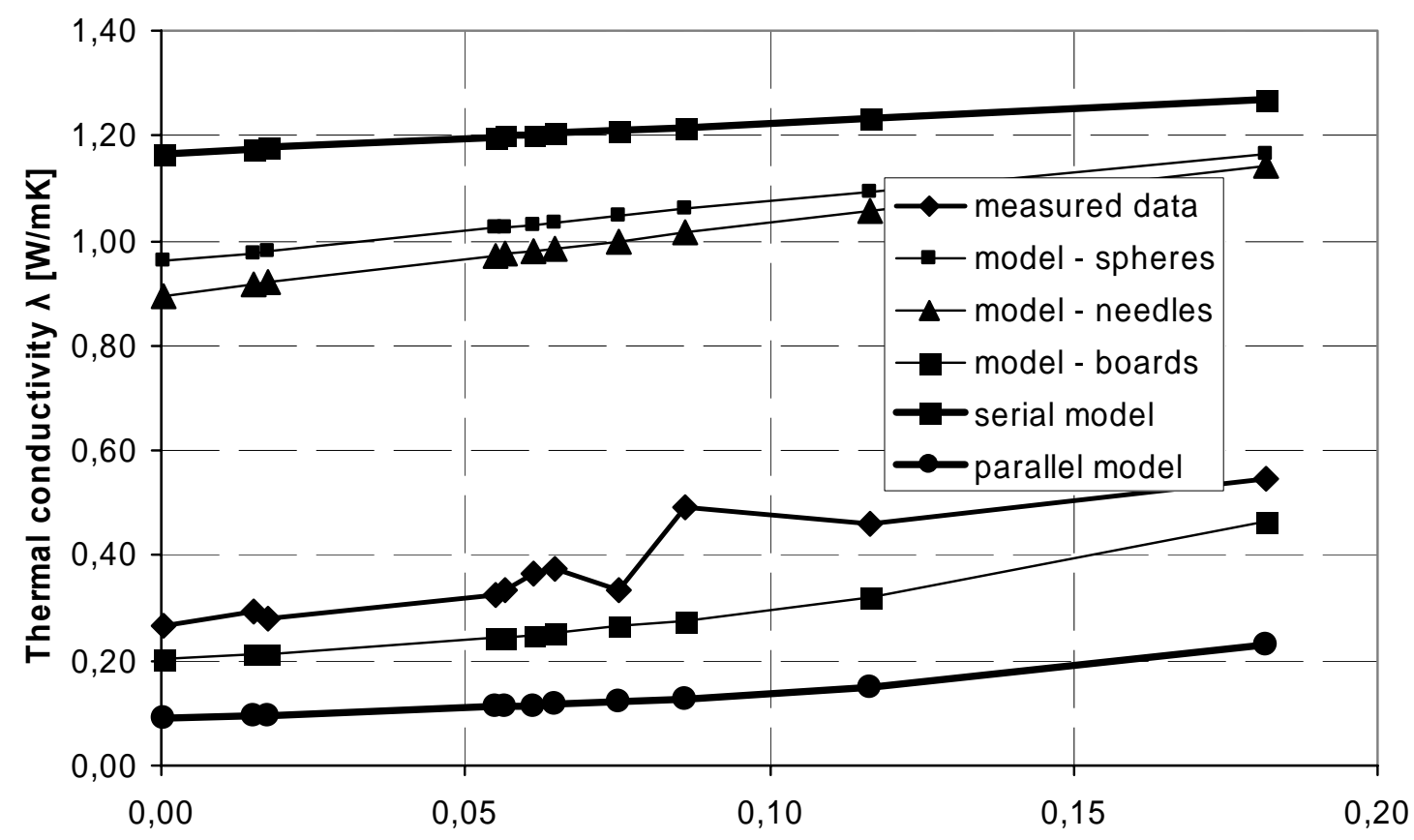

Volumetric moisture content $w\left[\mathrm{~m}^{3} / \mathrm{m}^{3}\right.$ ]

Fig. 4 Measured and calculated thermal conductivity of the sample exposed to $600^{\circ} \mathrm{C}$

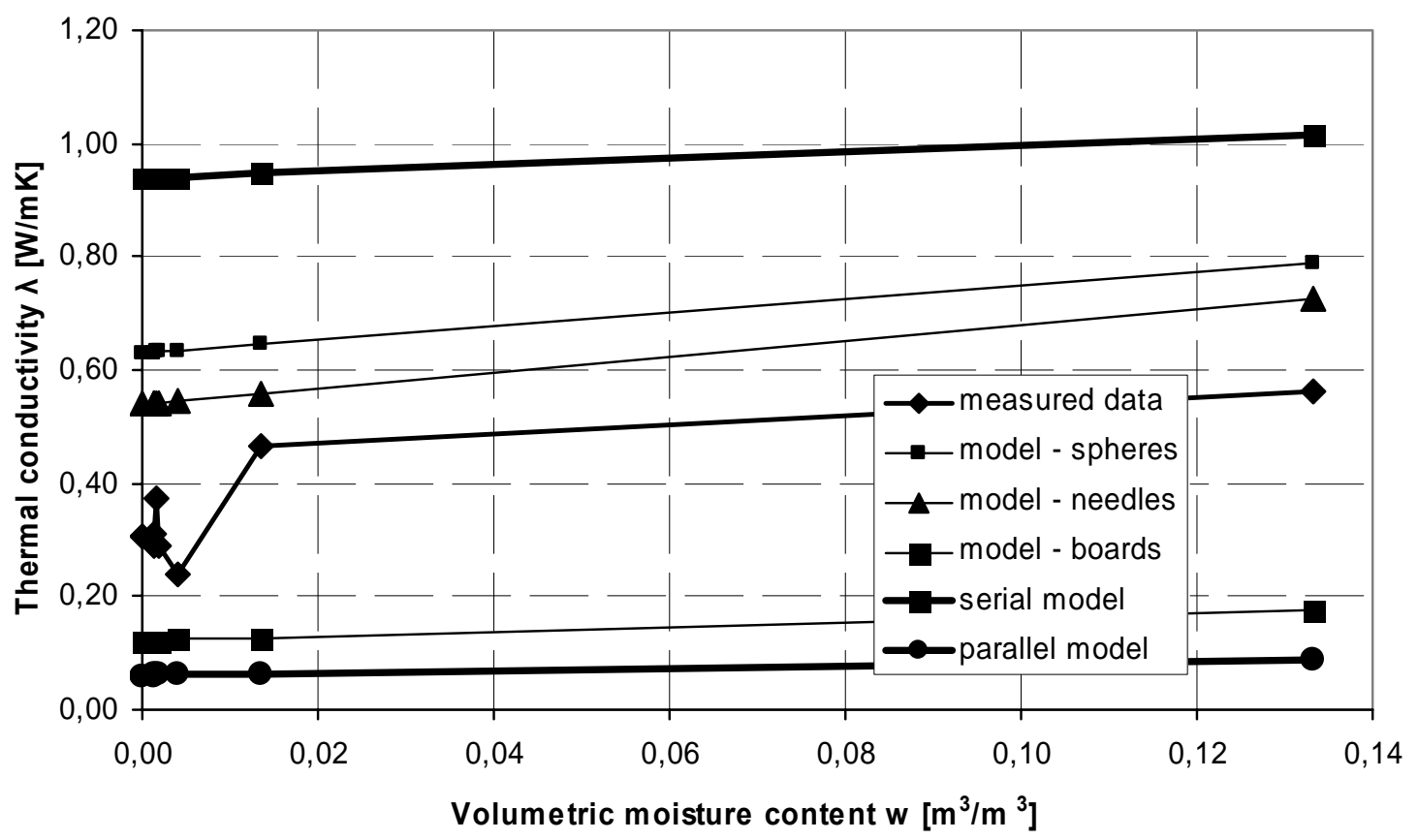

Fig. 5 Measured and calculated thermal conductivity of the sample exposed to $800^{\circ} \mathrm{C}$ 


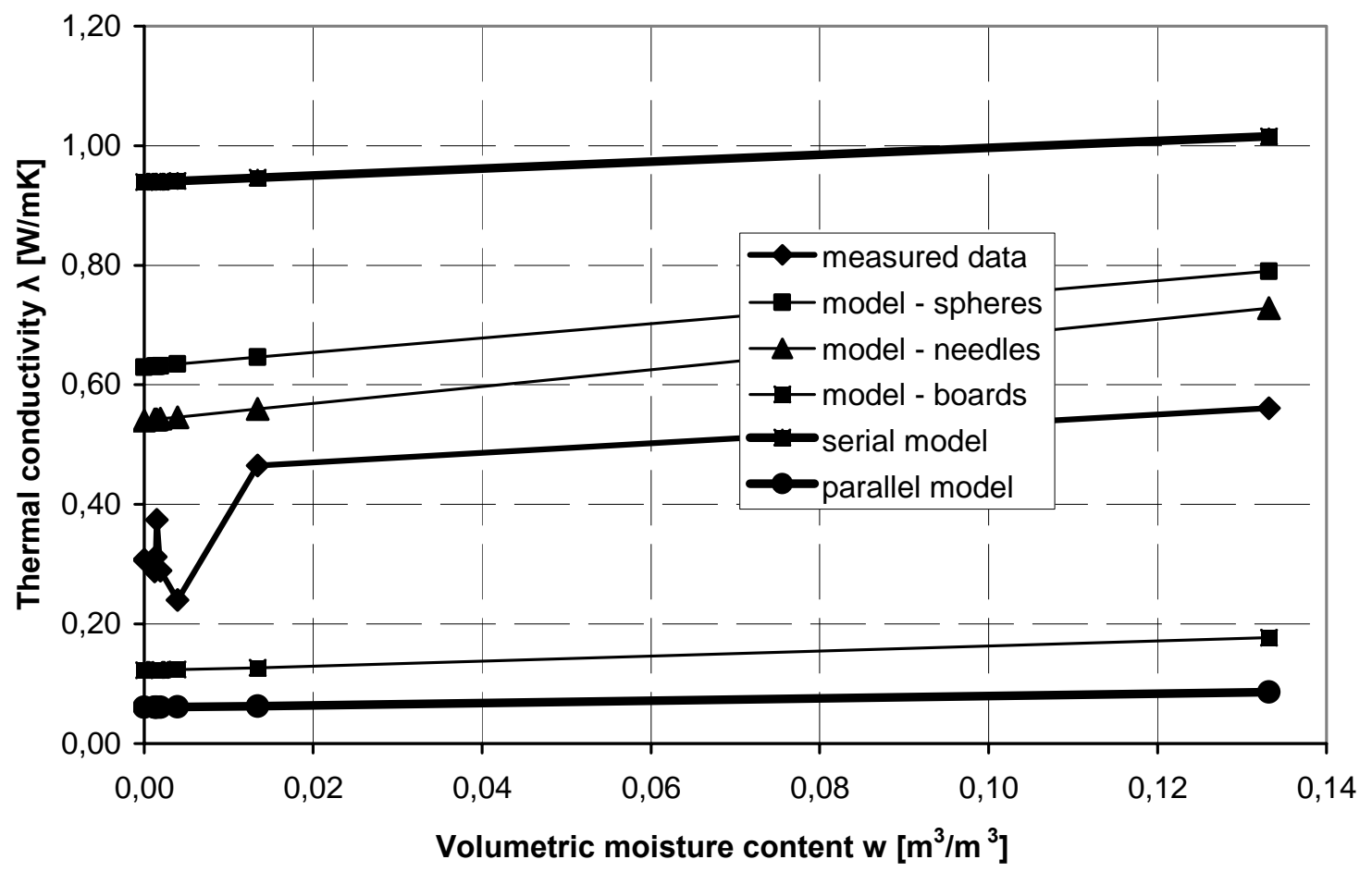

Fig. 6 Measured and calculated thermal conductivity of the sample exposed to $1000^{\circ} \mathrm{C}$

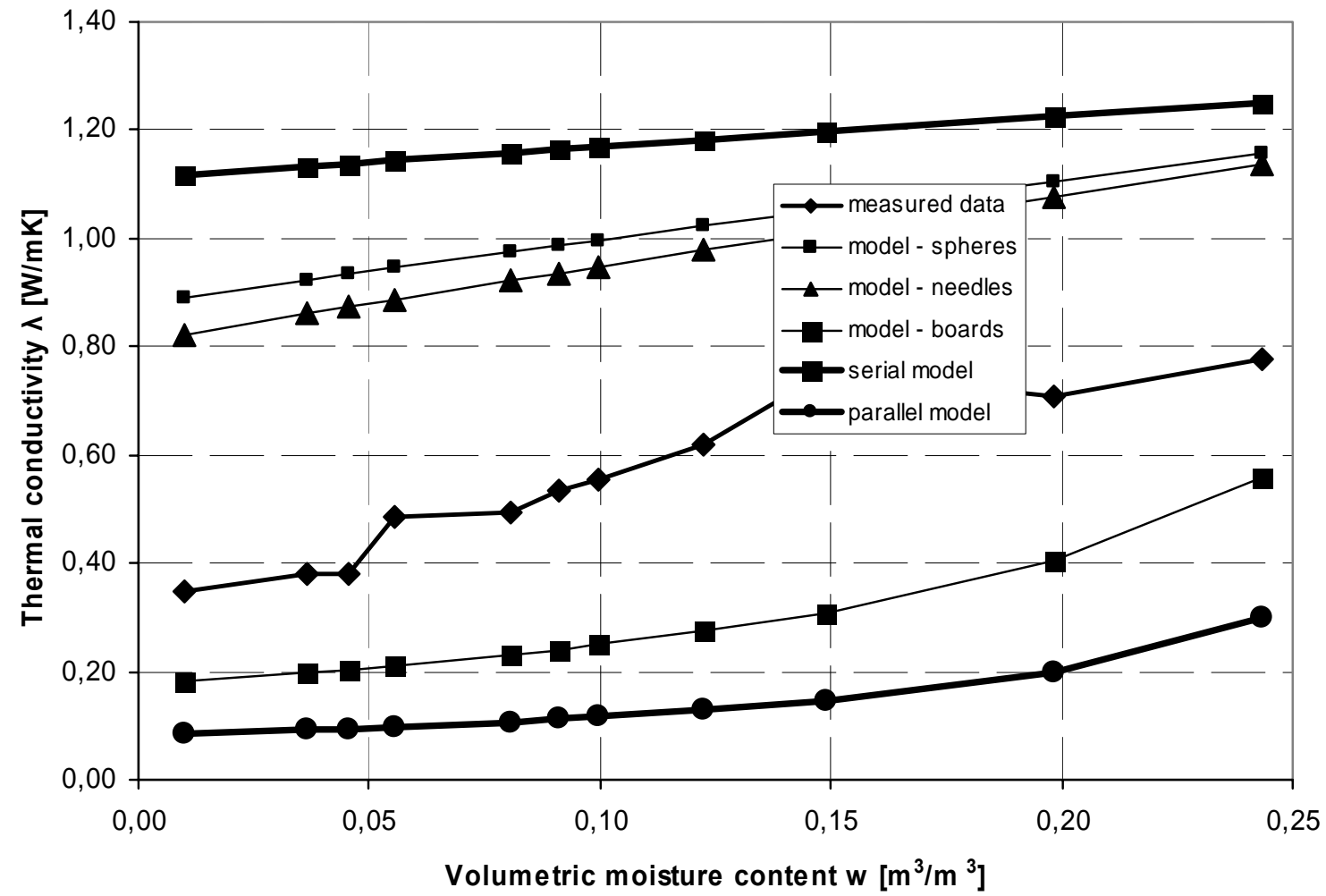

Fig. 7 Measured and calculated thermal conductivity of the sample exposed to tensile load 
Looking at the data from the point of view of accuracy of the analyzed Bruggeman-type mixing formulas we can see large differences between the particular types of inclusions. Systematically, the highest values of thermal conductivity were obtained for spherical and needle model, the lowest values were reached using the board model. This is a logical result because the board-shaped inclusions should lead to results closer to the parallel model than to the serial model (taken from the point of view of mixing thermal conductivities in Eqs. (5)(6), for the thermal resistances the serial-parallel orientation is naturally quite opposite, i.e. the serial model should be closer to the board-type inclusions).

The measured data were found in all cases between the spherical and board-shaped inclusion variants of the Bruggeman model. For the reference specimen and tensile load exposed specimens they were closer to the board inclusion model, for the thermal load exposed samples closer to the spherical inclusions model. This is in a good qualitative agreement with the change in the porous structure after thermal load found by mercury intrusion porosimetry measurements which was characterized by appearance of larger pores.

The analysis of obtained results from the point of view of the effect of moisture content on the agreement between the experimental and calculated data showed that all applied mixing formulas were sensitive to the moisture content in a very similar manner so that the slopes of the thermal conductivity vs. moisture content functions were similar.

\section{Conclusions}

Summarizing the measurements of thermal conductivity vs. moisture content functions of the carbon fiber reinforced cement composite in this paper, it seems surprising that the very significant difference in the pore distribution curves of the samples pre-heated to $600^{\circ} \mathrm{C}$ and $800^{\circ} \mathrm{C}$ resulted in only relatively small difference in thermal conductivity. However, the changes in the volumetric amount of pores and in the pore distribution were probably partially compensating each other. In the measurements throughout this paper, the higher porosity has led in all cases to lower thermal conductivity but the presence of larger pores resulted in an increase of thermal conductivity, probably due to the appearance of thermal bridges.

The application of Bruggeman-type mixing formulas for the calculation of thermal conductivity in dependence on moisture content was found to provide useful estimates of measured data. However, a unified formula could not be found for all material pre-treatment cases which were studied. This was probably due to the changes in pore distribution, particularly after thermal loading of the samples.

\section{Acknowledgements}

This research has been supported by the Czech Science Foundation, under grant No. $103 / 05 / 2376$

\section{References}

1. D. R. Lide (ed.), CRC Handbook of Chemistry and Physics, $79^{\text {th }}$ Edition. (CRC Press, Boca Raton, 1998).

2. R. Černý, P. Rovnaníková, Transport Processes in Concrete. (Spon Press, London, 2002).

3. A.M. Neville, Properties of Concrete. (Pitman, London, 1973).

4. Z.P. Bažant, M.F. Kaplan, Concrete at High Temperatures: Material Properties and Mathematical Models. (Longman, Harlow, 1996). 
5. IEA-Annex XIV, Condensation and Energy, Volume 3, Material Properties. (International Energy Agency, Leuven, 1991).

6. R. Černý, J. Maděra, J. Poděbradská, J. Toman, J. Drchalová, T. Klečka, K. Jurek, P. Rovnaníková, Cement and Concrete Research 30: 1267 (2000).

7. J. Toman, R. Černý, Acta Polytechnica 41: 8 (2001).

8. J. Grunewald, DELPHIN 4.1 -- Documentation, Theoretical Fundamentals. (TU Dresden, Dresden 2000).

9. R.M. Christensen, Mechanics of Composite Materials. (Wiley, New York, 1979).

10. A. Sihvola, Electromagnetic Mixing Formulas and Applications. (The Institution of Electrical Engineers, London, 1999).

11. A.A. Ogacho, B.O. Aduda, F.W. Nyongesa, Journal of Materials Science 38: 2293 (2003).

12. D.S. Smith, S. Fayette, S. Grandjean, C. Martin, Journal of the American Ceramic Society 86: 105 (2003).

13. J.D. Felske, International Journal of Heat and Mass Transfer 47: 3453 (2004).

14. F. Macedo, J.A. Ferreira, Review of Scientific Instruments 74: 828 (2003).

15. D. Polder, J.H. Van Santen, Physica 12: 257 (1946)

16. Lord Rayleigh, Phil Mag. 34: 481 (1892)

17. O. Wiener, Abh. D. Leipz. Akad. 32: 509 (1912) 